\title{
La virtud de la prudencia como herramienta que contribuye a una buena argumentación y a la praxis del mediador
}

\author{
The virtue of prudence as a tool that contributes \\ to good argumentation and the mediator's praxis
}

\author{
KARLA SÁENZ \\ Catedrática e investigadora Universidad Autónoma de Nuevo León. México \\ karla.saenzlp@uanl.edu.mx/https://orcid.org/0000-0002-7279-0342
}

ELSA ZURITA

Becaria del programa de Doctorado en Métodos Alternos de Solución de Conflictos. Universidad Autónoma de Nuevo León. (México) - elsa.zuritahr@uanl.edu.mx / https://orcid.org/0000-0002-8546-3076

Recibido: 25/10/2020

Aceptado: 26/11/2020

Resumen: Este articulo propone una comprensión de la prudencia que aporta a la mediación transformativa herramientas éticas, intelectuales y morales, por tal motivo, se considera necesario conocer cuáles son los elementos que componen su discurso autorregulado y argumentativo, considerando, las emociones, la lógica y la ética, poniendo especial énfasis en la participación del mediador/a, y la necesidad de orientar el conocimiento, teórico, técnico y reglamentario, hacia una práctica con altos principios; porque esto influye directamente en las partes intervinientes y en los procesos, y finalmente como conclusión, la incidencia de su aplicación en el desarrollo que mejora la práctica del mediador/a.

Palabras clave: Habilidad, Mediación transformativa, Mediador/a, Práctica, Prudencia, Virtud.

\begin{abstract}
This article proposes an understanding of prudence that contributes ethical, intellectual and moral tools to transformative mediation, for this reason, it is considered necessary to know are the elements that make up its self-regulated and argumentative discourse, considering emotions, logic and ethics, placing special emphasis on the participation of the mediator, and the need to orient the knowledge, theoretical, technical and regulatory, towards a practice with high principles; because this directly influences the intervening parties and the processes, and finally, as a conclusion, the incidence of its application in the development that improves the practice of the mediator.
\end{abstract}

Keywords: Skill, Transformative Mediation, Mediator, Practice, Prudence, Virtue. 


\section{INTRODUCCIÓN}

La idea de prudencia, que se remonta a los orígenes griegos de nuestra tradición filosófica, ha quedado progresivamente relegada hasta su disolución en el campo de la filosofía contemporánea (Aubenque, 1963), y no solo de la filosofía contemporánea paralelamente de la ciencias sociales, es necesario reconocer que en la ciencia actual, no suelen ser tomadas en cuenta por suposición teórica y de antigüedad, es por esto que se ha propuesto el recordar y el desarrollo de esta virtud para la práctica del mediador, ya que esta atiende al telos de esta profesión, que requiere sabiduría en la praxis.

Es así como esta virtud aporta para el fin de la profesión de mediar, que consiste no solo en saber actuar y hablar, sino saber el cuándo y el cómo hacerlo de acuerdo al momento presente, con un alto grado de coherencia, sirviendo como ejemplo para las partes que en estos procesos buscan a un guía y ejemplo que les ayude a resolver sus controversias, el mediador debe de saber desenvolverse con esta herramienta, ya que como menciona el autor, si bien no son nuevas, se consideran necesarias desde tiempos muy remotos para que el individuo pueda desarrollarse como un mejor ser humano, en beneficio de los demás, es por esto, que lo que pretende este articulo es demostrar que la prudencia tiene componentes que benefician profesional y personalmente, y estos elementos serán abordados desde diferentes autores posteriormente.

\section{LA NECESIDAD DE LA PRUDENCIA EN EL CONTEXTO ACTUAL}

Es importante contextualizar el concepto de la prudencia desde diferentes perspectivas filosóficas, uniendo así, las que se consideraron más importantes y que pueden beneficiar a la práctica del mediador transformativo. Se explicarán los inicios de este término, partiendo de los orígenes griegos y como diversos autores lo aplican en la actualidad, sin olvidar que el propósito y la esencia de esta virtud siempre será la coherencia al pensar, decir y obrar de acuerdo con la verdad, entendiendo la verdad universal que se muestra en todo, a través de la observación y la compresión de los contextos, teniendo como objetivo ayudar y beneficiar a los demás.

Es por esto, que tal virtud se considera indispensable, como habilidad que el mediador debe desarrollar y que contribuye no solo de forma profesional, sino en todos los contextos de su vida, ya que la forma que éste pueda intervenir con los demás, ya sea en palabra o acción, tendrá un impacto significativo en las vidas de los que convive, sin olvidar los te- mas tan delicados que trata, por eso, la importancia que sus acciones tengan el propósito del más alto bien.

"No sólo se precisa tener el conocimiento teórico episteme, sophia, sino sobre todo sabiduría práctica techné, phronesis". En este sentido, la prudencia ayudaría a aplicar la regla general a la situación particular. (Moreno Villares, 2014, p.105)

\section{LA PRUDENCIA COMO HERRAMIENTA QUE CONTRIBUYE A UNA BUENA ARGUMENTACIÓN}

Es relevante entender la argumentación, para poder regular la palabra, en sus modalidades oral y escrita, en cuanto a lo que se produce y como se analiza, partiendo de principios de hacer y decir de manera prudente y ética, en relación a como se dicen las cosas, de acuerdo en su mayoría a la retórica de Aristóteles, "es necesario hacer de la argumentación un ejercicio equilibrado a través de la prudencia, que es un modo de ser del orador y la principal característica de credibilidad de su discurso, así como una forma de transmitir sus razonamientos a quien le escucha y con la base del bien común" (Malaver \& Moreno, 2019, p. 83), en este sentido lo que es más conveniente para todos.

Aristóteles es quien le da una nueva concepción y establece principios sobre los cuales, esta técnica de argumentación se desarrolla de forma más eficiente. Para este filósofo, "la retórica ideal sería aquella de la que surgen atenienses bien pensantes, personas virtuosas que fueran capaces de instruir para bien y de forma comprometida con las necesidades de la ciudad, para conducir a las almas a desear lo verdadero y obrar en todo conforme a ello" (Racionero, 1999), es así como la concibe como lo que puede ser mas conveniente en cada caso.

"La retórica, a partir de Aristóteles, tendría mayor orden procedimental al regularla con una serie de tratados o reglas que conforman un discurso" (Plantin, 2015), así comienza a construir las bases de la comunicación en tres elementos: el que habla, a quien se habla y lo que se dice, de estos surgen tres pilares fundamentales para la retórica; el ethos, el pathos y el logos.

El ethos que es la representación del ser, la forma en la que un individuo rige su conducta y define su personalidad, el pathos lo que se dice y el impacto que esas palabras tienen para provocar sentimientos en otras personas que están escuchando, y finalmente el logos que es todo lo que se dice desde el pensar, la palabra razonada y medida; y así de estos pilares nace la base de la retorica y en conjunto conforman la prudencia. 
Para (Malaver \& Moreno, 2019, p. 83) la temporalidad de la retórica reside en sus tres géneros discursivos, pues cada uno atiende a un momento específico del tiempo, del cual se obtienen argumentos, evidencias, ejemplos, hipótesis y constataciones, estos géneros explican que, dependiendo el tipo de oyente, el escenario y los temas a tratar, ya sean de la vida pública y a las necesidades prácticas, se usan de acuerdo con una retórica en particular que (Aristóteles, 2000) propone, siendo las siguientes.

El judicial: corresponde, en un sentido convencional, a escenarios de carácter político, en los que se da la producción de prescripciones que, traducidas en leyes, regulan las normas sociales sobre las que se tiene que regir la vida pública, apelando siempre al mejor criterio, en este sentido, los mediadores adaptan sus discursos de acuerdo con principios éticos que parten de una ley, y a su vez de un procedimiento, para poder cumplir con la normatividad correspondiente al ejercer su profesión. Entendiendo las opiniones de los intervinientes $y$, hacerlos que se apeguen a estas normas, de forma más equilibrada y razonada posible.

Lo epidíctico: que ilustra una lógica inductiva, tiene que ver con los arquetipos, o los ejemplos dignos de imitar y promover en sociedad. Ya que trata de lo honroso y lo deshonroso, se encarga de dar juicios de valor a las acciones y también a quienes las ejercen en el presente.

Junto con sus atributos y sus virtudes, está claro que los mediadores son el ejemplo que seguir en los procesos que liderean, por eso se vuelve indispensable que el discurso que imparten sea lo más asertivo posible, ya que tienen gran impacto con los intervinientes, que esperan de ellos una conducta lo más ética posible.

La deliberación: se pueden distinguir los argumentos de causa y efecto, que se construyen en la proposición de manera condicional, son los mediadores los que tienen que aconsejar a los intervinientes sobre las posibles consecuencias de sus acciones, en este sentido, siempre se tiene que apelar al mejor criterio o a lo más conveniente posible. Es por medio de la buena argumentación y la prudencia, que se logran los a acuerdos con las partes.

\section{PATHOS, LOGOS Y ETHOS: EN EL DISCURSO DEL MEDIADOR TRANSFORMATIVO}

Los intereses en los estudios de Aristóteles de la retórica estuvieron ligados a la manifestación de la belleza y a la estructura de la poesía. Aunque Aristóteles reafirme la autonomía en las disciplinas de la Poética y la Retórica, también reconoce que éstas dos tienen ciertos "campos en común"
(Suñol, 2007, p. 79), y es en esta búsqueda que se consideran los siguientes principios de acuerdo con las reflexiones de (Malaver \& Moreno, 2019, p. 85)

Pathos: este tiene que ver con la disposición del orador sobre la audiencia, es decir, que de la actitud de quien habla se pueda adecuar a la actitud del mismo público, de quien escucha lo que se dice, a la vez que el orador también puede influir en el comportamiento de dicho público, es por esto, que el mediador debe ser consciente de esta disposición, cómo influye, transmite sentimientos y emociones a las partes.

El humor del mediador en la práctica impacta directamente en las partes y en el proceso, la palabra se mueve en el mundo de las emociones y de acuerdo con la emoción del momento, puede afectar en el juicio de quien las escucha, es por tal motivo que Aristóteles la consideraba como una máxima.

El logos: es el principio racional del discurso, que tiene que ver con la lógica argumentativa, que es con la que se construyen los argumentos, esto parte del conocimiento que se tiene del caso, proceso, normas, leyes o reglamentos, según aplique el caso.

Como el mediador usa esas herramientas de manera lógica, construye una relación coherente entre los elementos que tiene a su disposición, para que pueda llegar a determinadas conclusiones, logrando que su discurso tenga una relación lógica y de forma razonada para lograr que las partes estén de acuerdo.

Ethos: en este principio surgen las intenciones de la palabra de parte de quien habla, para Aristóteles no es suficiente que esta cautive y persuada, pues si se retoma lo de lo más conveniente para todos, las intenciones del orador se encaminan a garantizar una causa mayor y prioritariamente social: la del bien común, es la ética del mediador, la que debe saber diferenciar lo que concierne a un bien publico y privado y evitar todo tipo de prejuicio, apelando siempre al principio de la verdad y del ethos es donde más se desprende la prudencia, ya que representa palabras y acciones.

El mediador al desarrollar estos tres principios logrará constituir una palabra razonada, en términos de Aristóteles, la retórica además apelar a la palabra en emoción influye en el ánimo de los intervinientes con transparencia en honor a la verdad, para las personas que los escuchen, es por esto, que se menciona la importancia de estos tres principios, para que el mediador mejorare su práctica de forma prudente y ética, y así es como, es necesario que el orador prudente desarrolle la habilidad de maestro y que logre transmitir una verdad y una forma de llegar a ella, para las personas que los escuchen,, 
"en términos de educación, de quienes sean sus discípulos, sean ciudadanos bien pensantes, que reproduzcan con otras audiencias, este tipo de discurso, que es el de la prudencia" (Malaver \& Moreno, 2019, p. 88).

Es importante destacar que se requiere prestar especial atención en lo que se va a decir, de manera que no se preste a malas interpretaciones, ni confusiones, para que los discursos o intervenciones, de los mediadores sean entendidos por los intervinientes y esto debería garantizar mutuo entendimiento para que las partes estén satisfechas, en este sentido la estructura de la retórica aporta a este fin.

\section{LA PRUDENCIA COMO PRAXIS EN LA MEDIACIÓN TRASFORMATIVA}

Si analizamos la prudencia desde el enfoque de la praxis, entendiendo los elementos que componen esta virtud intelectual, acompañada de razonamiento, que permite a través de la experiencia del alma, permita saber discernir que es lo mejor partiendo de generalidades que conllevan conocimientos teóricos y metodológicas, para así saber que es lo aplicable a cada acción en particular, procurando siempre que todo sea en beneficio de los involucrados. Por tal motivo, se pone de manifiesto la contribución de los siguientes autores con la finalidad de poder determinar, que elementos de los que proponen son aplicables y contribuyen a la practica del mediador transformativo.

Aristóteles define la prudencia como "aquella disposición que le permite al hombre discurrir bien respecto de lo que es bueno y conveniente para él mismo" (Aristóteles, 2000, p. 86), es así que se vuelve menester en los mediadores comprender lo que es adecuado y oportuno para ellos mismos como individuos, porque en función que el profesional lo entienda podrá determinar en qué manera puede contribuir apropiada y oportunamente con los demás, pero sin este saber interno y personal, le será imposible llegar con objetividad a conocer el bien que los demás involucrados necesitan para sí, y para llegar a tal punto, se requiere en gran medida de esta virtud y conocimiento, así, es prudente el hombre, prosigue Aristóteles, "no en un sentido particular, como para la salud y el vigor del cuerpo, sino sobre las cosas que deben contribuir de modo general a su virtud y felicidad" (Aristóteles, 2000, p. 90).

Según la definición aristotélica de (Aristóteles, 2010), la phrónēsis es una héxis práctica, verdadera, acompañada de razón y se refiere a los bienes humanos, es importante entender que este filosofo la define de la siguiente manera:

Es una disposición habitual. Se acompaña de razonamiento. Es verdadera. A diferencia de otras virtudes, esta es práctica. Se refiere a los bienes humanos.
"La phrónēsis se refiere a los bienes humanos y que tiene la doble función de gobernar a las pasiones y de procurar las condiciones óptimas para la contemplación"(Araiza, 2009), es así como la prudencia logra que se den las mejores condiciones para la vida política, personal y profesional impactando en diferentes contextos y para la vida contemplativa, la prudencia le permitirá al mediador construir relaciones de entendimiento y armonía con sus cercanos y con las personas con las que intervine en los procesos, logrando así contribuir a la sociedad y a la vida política en general, tal como lo expuso Aristóteles.

Para (Araiza, 2014, p. 151), "la phrónēsis es una especie de héxis, una disposición habitual, un hábito o una posesión y debe contener dos características que son la epistèmē, entendida como un saber sobre el conocimiento teórico y científico, y por otro lado, la téchnē la destreza o habilidad para poder llevar acabo dichos conocimientos teóricos" y se podrá decir que el mediador posee la prudencia en medida que se desarrollen estos conocimientos y la habilidad para aplicar estas destrezas de forma práctica en la profesión.

Es necesario que se comprenda la héxis como una práctica del individuo que incluye disposiciones tanto morales e intelectuales, que se llevan a cabo día a día, es una virtud transversal y el desarrollarla implica aplicarla en todos los contextos de la vida, "de ahí que la phrónēsis (prudencia) sea una especie de disposición habitual (héxis), pues es conocimiento. Y puesto que es un conocimiento que se orienta hacia la acción, hacia el aquí y ahora, es entonces un conocimiento práctico." (Araiza, 2014, p. 56),

Se debe tener claro porque las virtudes son importantes en la profesión del mediador, en este sentido no basta solo con poseer el conocimiento científico que aporta la misma profesión, se debe poseer una excelencia intelectual, que es la que marca el camino para ser no solo mejores seres humanos porque se actúa con la finalidad de un bien social, si no también mejores profesionales.

La prudencia tal como nos dice (Chillón, 2019, p. 133), "tiene que estar orientada por la virtud intelectual, por la virtud dianoética que viene determinada por la racionalidad de los fines y por la verdad práctica: la verdad que se refiere a la vida humana en cuanto ha de desenvolverse en la práctica (y, por tanto, distinta de la verdad esperable de la ciencia física o de la matemática)", es esa combinación de destrezas y habilidades, pero sobre todo esa capacidad humana propia del alma, que ayuda a determinar y entender el bien que es necesario para cada caso en particular, que se debe aplicar.

Es necesario saber tal como lo explica (Araiza, 2014, p. 160), que, la "prudencia es una especie de adquisición del 
alma, análoga a la que se da en el caso de la percepción sensorial y de los sentidos". Es necesario saber que para poder desarrollarla se requiere de la experiencia, ya que ésta se desarrolla dentro del alma, por las vivencias que atravesamos, así mismo, de la percepción de los sentidos al observar los sentimientos y posiciones de los involucrados en un proceso de mediación en nuestra practica.

Después de un largo periodo de aprendizaje, "es la experiencia en nuestra práctica la que hace posible la prudencia necesaria para determinar en qué momento es oportuno y que es pertinente aportar en dichas intervenciones", también nos dice (Chillón, 2019, p. 161), referente a la experiencia que el ejercicio de la razón y la vida humana vivida en verdad exigen la puesta a punto de disposiciones prácticas orientadas por ingredientes como: la instrucción o el conocimiento, la memoria de la experiencia pasada y vivida, la circunspección y, por tanto, el análisis de las circunstancias concretas, así como la necesidad de sopesar los riesgos que conllevan y, por último, la aplicación de la ley general o universal al caso particular.

La prudencia, tal como lo dice Aristóteles, tiene por objeto lo humano y aquello sobre lo que se puede deliberar; en efecto, afirmamos que la operación del prudente consiste sobre todo en deliberar bien, y nadie delibera sobre lo que no puede ser de otra manera, ni sobre lo que no tiene un fin, y este consiste en un bien práctico, por tal motivo, el ser humano y el profesional prudente deberán tener esta experiencia que se obtendrá a través de la práctica para poder ejercer mejor en cada situación que se le presente y, como norma indispensable conocer la verdad desde el contexto de procesos, normas, ciencia que sea aplicable según la profesión, es decir, partir de lo general, para saber aplicar lo más cercano a una acción correcta en lo que a cada situación en particular concierne, entendiendo las contextualidades aplicables a cada individuo con el cual tenga interacción, para poder tomar las acciones que considere pertinentes en función del conocimiento de la verdad observable, y con un fin que no se debe olvidar, el cual, siempre será de una u otra manera apoyar con su práctica a los demás individuos.

Para (Moreno Villares, 2014, p. 105) es una virtud intelectual y moral que le dispone habitualmente a elegir lo que hay que hacer en una situación moral concreta, es la capacidad de deliberación, de sensatez para buscar ser siempre la mejor persona posible y hacer la mejor acción posible.

Aunque es imposible determinar como actuarán los mediadores y cuáles serán sus acciones en un acontecimiento en concreto y prever todas las circunstancias, la forma de actuar sobre todo en momentos difíciles, será un salto creativo al vacío y dependerá mucho de los profesionales en particular, además cada situación que será única, por tanto, la forma de actuar de los mediadores va más allá de los principios, normas o metodologías, es por ello que el mediador deberá desarrollar la habilidad para leer objetivamente las circunstancias y los contextos en los cuales se vea involucrado en su práctica.

Además de tener un buen juicio para poder decidir lo mas adecuado a la acción correcta, acompañado de la responsabilidad correspondiente, es necesario saber que una vez que el mediador pueda desarrollar la prudencia y la lleve a la practica esta nunca podrá olvidarse, ni dejarse de lado, es un conocimiento adquirido del alma, caso contrario con aspectos técnicos o teóricos.

Así se vuelve menester desarrollar la phronesis como la conexión entre las virtudes intelectuales y las virtudes morales. Otra acepción la relaciona con la bondad, con la capacidad de obrar bien. Por último, "las virtudes, la prudencia también, pueden ser aprendidas, pueden enseñarse". (Moreno Villares, 2014, p. 110), es necesario resaltar que no sólo se trata de una cuestión intelectual y moral, no se debe pasar por alto que al estar obrando a través de la bondad, el resultado deberá estar encaminado a lo mejor, no solo para las partes, si no también a la satisfacción personal profesiona, dando tranquilidad y paz al alma, que solo la prudencia puede dar, actuando bajo la dirección de ésta podrá ser de alguna manera impregnada a todas las personas con las que el mediador se relaciona.

Es necesario saber que, "la prudencia es la que le ayuda a aplicar la regla general en la situación particular. No sólo eso, la dirige hacia que la acción sea además de técnicamente correcta, buena. Se convierte así en una conexión entre las virtudes intelectuales y las virtudes morales" (Lorenzo Izquierdo, 2019, p. 75), en este sentido los facilitadores deberán tener en equilibrio estas virtudes que le permitirán desenvolver mejorar su profesión, así, la prudencia aparece como una actitud ética, definida por la meta de la transformación de sí (Deleuze, 2005), y es en este sentido que en cuanto se sigan desarrollando con diversas herramientas que les permitan mejorar en su práctica, van a contribuir al fin de la mediación transformativa, ya como se mencionó en capítulos anteriores que uno de sus pilares se centraba en la practica de los facilitadores.

Es importante saber que la prudencia también es la facultad de emitir órdenes con vistas a la acción, y cada acción es particular, de modo que es también tarea de ella conocer las circunstancias particulares que rodean la acción; pero, además, la prudencia misma supone ya el conocimiento práctico universal, el cual se adquiere con el concurso del tiempo. 
Según (Araiza, 2014, p. 152), "las virtudes en general no siempre son innatas", como se menciona en apartados anteriores, al identificar esas fortalezas y debilidades que desea desarrollar las adquirimos por un proceso de aprendizaje consciente teniendo en cuenta el fin, el tiempo dará la experiencia y en determinado momento cuando estas virtudes ya estén dentro nosotros arraigadas e interiorizadas, dentro de nuestra alma se traducirá en sabiduría en la práctica, sabiendo que se es prudente, no solo por disponer de todos los conocimientos científicos, teóricos, destrezas o habilidades, si no porque se es capaz de actuar de forma correcta en el momento, por eso, en la conexión de lo insuperable del aquí actual y de la plenitud a la que se aspira reside esa sabiduría virtuosa, "la phrónesis en cuanto estructura que permite al hombre apegado a la tierra no desconectarse de su tendencia hacia la eudaimonia" (Chillón, 2019).

La sabiduría del phronimos es sabiduría como tal y, por tanto, no es mera utilidad, no es cálculo frío, no es pura estrategia. Al ser sabiduría del logos y constituir este el campo de la sociabilidad esencial de la naturaleza humana, como lo explica (Aristóteles, Retórica, 2000), la phrónesis se presenta como una areté dianoética para la convivencia, una herramienta esencial que permite que se logren mejores relaciones interpersonales en todos los aspectos de la vida, teniendo como resultado interacciones con los demás positivas que lograran un convivencia armónica con todas las personas que se relacionen ya que como fin tiene el obrar el bien en los demás.

La interpretación de la prudencia muestra cómo se constituye este ente que es el Kairós, la conducta y la práctica deben de ser siempre concretas y obedecer a la forma del trato que se preocupa por el mundo (Heidegger, 2002), es por esto, que la práctica del mediador tiene que estar acompañada no solo de las habilidades y conocimientos antes mencionados anteriormente, un saber que le permite intervenir, opinar, guiar a las partes cuando sea necesario, cuando es el momento oportuno para hacerlo, con el telos de la práctica para establecer un orden que permita que los intervinientes se transformen en mejores seres humanos de los que llegaron a ser cuando tenían el conflicto. Explica Heidegger que tiene que estar acompañada de cierta preocupación por el mundo y en este sentido los Mecanismos aportan a esta virtud y viceversa, ya que las dos tienen como propósito mejorar la interacción de las partes, construir nuevos caminos para tener una sociedad mas armónica.

Para (de la Oliva Santos, 2012, p. 243), a la hora de las decisiones, "la prudencia es un hábito esencial para orientar la conducta o comportamiento, es el puente entre lo inte- lectual y lo agible, entre las ideas y la acción". En nuestro caso, la prudencia habría de ser siempre la clave para decidir, a partir del conocimiento, de la ciencia, pero ponderando todos los aspectos de la realidad que el mediador observa en un proceso, por tal motivo, no basta tener estas habilidades ya intrínsecas en los mediadores es necesario, introducir nuevas formas de comportamiento que orientan a la hexis de los mediadores.

La persona y el profesional que obren con prudencia mostrará "ante los demás su carácter civil, por lo que con madurez asume la autodeterminación y el autocontrol de sus actos tan necesario para el bienestar de todos" (Muñoz, 2006, p. 223), y es ese mismo bienestar por el cual los mediadores no deben de perder la sensatez, ya que es su posición la que permite que en los procedimientos de mediación se logre el equilibrio, es su manera de conducirse la que influye en gran medida el procesos, si bien no es el quien decide, las partes acuden ahí por un motivo en particular que es resolver sus diferencias y el mediador sirve como guía y ejemplo.

El actuar con prudencia en la búsqueda individual de nuestros propios intereses lleva obligatoriamente a la discusión de las ideas, juicios y percepciones que se tienen, es decir, a buscar el consenso, pues la felicidad de todos es tarea de todos, no de individualidades, ya que mí razón puede ser incapaz de conocer en qué consiste dicha felicidad pública y menos aún de saber cuáles son los medios más adecuados para alcanzarla, por lo que la sociedad, como un todo, demanda de estancias para el diálogo y el consenso, demanda de instituciones capaces de mantener, fomentar lo que es realmente bueno para todos y velar por que lo acordado se cumpla (Muñoz, 2006, p. 225), tal como nos dice este autor la mediación pude ser vista como el punto de inflexión que da lugar a este intercambio de ideas y formas diferentes de percibir la vida, además es el lugar en el que los intervinientes buscan la armonía, y desarrollarla implicaría que la capacidad de contribuir a lograr el equilibrio y a mejorar las relaciones de las partes.

Vemos, que las virtudes se manifiestan e influyen en todos los ámbitos de la vida del individuo. Si bien nacen o se dan inicialmente en las prácticas, su alcance es mucho mayor: la vida como unidad con su 'telos' y el razonamiento práctico (Maclntyre, 1984), es por esto que el alcance de la prudencia tendrá un alcance no solo en el ámbito profesional del mediador podrá permitirle ser un mejor ser humano, conservar mejores relaciones, en todos los contextos de su vida esta virtud y todas las demás deben de ser consideradas como algo transversal y que de su impacto positivo en muchos sentidos.

Pero, finalmente, viene a decir, que las virtudes influyen en la actitud o reacción del individuo en distintas situaciones, 
en las relaciones sociales y en el razonamiento práctico de todo agente (Maclntyre, 1999), y si los mediadores tratan caso a caso con temas y experiencias tan complejas, con dificultades debido a las reacciones de los demás, entre mas herramientas internas desarrollen los mediadores mejorará la práctica.

En Three Rival Versions of Moral Enquiry (Maclntyre, 1990), define la prudencia como la virtud consistente en ser capaz de remitirse, en las situaciones particulares, a los universales pertinentes y actuar de modo que el universal se encarne en el particular, por tanto aquí se puede destacar la importancia que la prudencia permite a los mediadores conectar los principios generales de mediación a lo particular, es decir, saber actuar en una situación que exige partir de determinados principios, que pueden llamarse procesos, procedimientos o la misma ley.

Para (Maclntyre, 1988) en Whose Justice?,define la prudencia como el ejercicio de la capacidad de aplicar verdades acerca del bien para tal o cual tipo de persona o para personas en general y en ciertos tipos de situaciones a uno mismo en ocasiones particulares. El 'phronimos' es capaz de juzgar no sólo qué verdades son relevantes para él en su situación particular, sino que también, a partir de ese juicio y de su percepción de los aspectos relevantes de sí mismo y de su situación, cómo actuar rectamente, es así como la aplicación de la prudencia en diversos escenarios que permitirán al mediador actuar de forma que no solo busque el beneficio para el en particular, es desarrollar la habilidad para en todo momento tener conciencia que este bien debe ser aplicado en beneficio de los demás, es decir que el mediador a de conocer cuales son las verdades particulares de su practica ya sea de forma teórica o científica y sabrá aplicar este conocimiento para la acción en particular, es decir, que esto no supone a una especulación teórica, aunque ya la conozca, el deberá saber ejecutarla bien a un acto en concreto, es decir saber llevar una buena práctica.

Se puede decir que "es la prudencia, podemos concluir la que da al individuo la cualidad para saber gestionar y resolver dicha situación" (Lorenzo Izquierdo, 2019, p. 106), y es así como se puede apreciar la importancia que el actuar bajo esta virtud permite a los mediadores ejercer su práctica de la mejor manera y en todos los aspectos de su vida, decir que se debe saber como resolver la situaciones es tarea fácil, pero no hay que olvidar lo complejo de la profesión por los temas tan diversos y tan personales de los intervinientes en particular a tratar.

El mediador requiere practica que sea consciente, para no olvidar la finalidad y el propósito de la profesión que está ejerciendo, la regla para la acción es la prudencia, que debe intervenir para evitar que el proceso del deseo se deforme en sujeciones aún más profundas, o bien, en alguna forma de autodestrucción. (Antonelli, 2013, p. 89).

La 'phronesis' une lo particular y lo general y es esencial para establecer y definir correctamente lo general, lo universal, uniendo así lo teórico y lo práctico (Maclntyre, 1988), es así como los mediadores podrán desarrollar sabiduría en la practica desde el enfoque de la prudencia, beneficiado a la ciencia, el proceso y a las partes intervinientes, es por lógica que la ausencia de esta virtud tenga implicaciones notables que no solo impactaran a una investigación racional, pues podría impedir llegar al telos de la ciencia, investigación o el ejercicio de la profesión.

De acuerdo con el pensamiento de Maclntyre, podemos decir que la importancia de la virtud de la prudencia radica en tres puntos.

Esta aporta al individuo para saber que principios generales puede aplicar a una situación concreta, de modo que permite distinguir que es lo más relevante en una situación particular según el bien buscado.

Las reglas, normatividades, definición de procesos y aplicación de estos requieren directamente de la prudencia, una acción correcta concreta no es producto de aplicar estas acciones, sin ser definidas previamente por la prudencia (Sáenz, 2016).

La carencia de esta virtud tiene implicación de connotación negativa para el proceso de definir investigación, procesos y normas, sin ella, no es posible para el individuo avanzar en el conocimiento intelectual y, en concreto, en la investigación moral.

Se puede deducir que son las virtudes las cualidades que hacen fructíferos, honestos y progresistas los debates y la argumentación dentro de una comunidad y de una tradición; y que son ellas las que mantienen la vida y el dinamismo de una tradición como cuerpo de diálogo y transmisor de conocimiento (Maclntyre, 1984), por lo cual son cualidades que requieren los mediadores por las características que requiere la profesión, el desarrollo de mejores personas, que tengan relaciones en base a un conocimiento teórico y un profundo conocimiento humano.

Ahora bien, las normas que ponen los límites, que guían hacia el bien, marcan pautas de conducta, pero estos principios son guías generales de comportamiento, y al ser normas generales no determinan por si mismas como se puede actuar y comportarse en una situación concreta correctamente, solo se define el tipo de bondad a la que se aspira y como estas normas o leyes depende principalmente de la práctica 
para saber determinar lo que es bueno o no, en este sentido la prudencia ayudara a cumplir esta normatividad, sin esta virtud aprendida previamente que permita al mediador saber dirigirse bajo estos principios y determinar en qué momento es mejor aplicar cada uno según corresponda al momento oportuno.

\section{LA PRUDENCIA EN EL MEDIADOR TRANSFORMATIVO.}

Ahora que ya se han analizado los elementos de la prudencia, tanto en la argumentación como en la praxis, que contribuyen a la mediación para lograr que estos presupuestos se den, se pueden resaltar algunos postulados bioéticos que han sido desarrollados por (Hoyos, 2005), que aportan en este sentido en el contexto de la conciliación médica, y de igual manera pueden ser aplicados en la mediación trasformativa.

Realizar un buen contacto: este consiste fundamentalmente en el encuentro empático con las partes, la atención que se les brinde, el despertar en ellas la sensación de apertura para entender el conflicto, y el ámbito de cercanía familiaridad y compromiso creado. Ello requiere un despliegue de cordialidad, y seguridad para inspirar confianza, facilitar un clima propicio y un ambiente de interacción.

Saber escuchar: consiste en atender en forma imparcial el llamado de las partes comprometidas, desplegar un comportamiento igualitario de comunicación verbal y no verbal con cada una de ellas, infundir la confianza suficiente, saber recibir los distintos tipos de comunicación, oír las razones que presentan, ser buen observador y mantener una escucha activa.

Intercambiar: para ello debe tener la suficiente experiencia en el manejo de las relaciones interpersonales, conocimiento no solo de la personalidad de las partes sino del entorno social, económico y cultural; debe, asimismo, saber jerarquizar prioridades, tener paciencia, tolerancia a la frustración y un buen manejo de la ansiedad.

Conocer el conflicto: estar debidamente enterado de la situación de controversia e identificar el centro del conflicto, el querer de cada parte y las posiciones asumidas por ellas, así como las razones que motivaron el problema. (Pastor, 2011, p, 82).

Ser orientador y facilitador y no juez de las partes: es decir, indicar las distintas vías o caminos que se pueden utilizar en la aclaración del conflicto, lo que implica una actitud facilitadora que permita encontrar salidas, mostrándose prudente y amistoso pero firme y concreto en el problema.
Hacer énfasis en las personas: implica tener en cuenta que los conciliantes son seres humanos con sentimientos, valores emociones y puntos de vista diferentes. Propender por una "hermenéutica del discurso": quiere ello decir que, en la ventilación del conflicto o problema generador de desacuerdo, el conciliador debe propiciar la lectura interpretativa de las posiciones externas, trabajo que exige un recorrido de interpretación y comprensión a partir de sucesivas argumentaciones sobre el fenómeno en cuestión.

Generar alternativas: consiste en crear distintas posibilidades de interpretación para que cada lectura del conflicto sea en verdad una dinámica de expansión que permita a la par de la lectura hermenéutica.

Es la virtud de la prudencia la que debe lograr que estos postulados se lleven a cabo en el acto de la mediación transformativa, el telos del mediador transformativo siempre será llevar su práctica dirigida con los mas altos principios, éticos, morales e intelectuales, y es la prudencia la que colabora para que este fin sea llevado a cabo, son la praxis y la argumentación de acuerdo al logos, pathos y ethos que logran que la práctica y el proceso del mediador transformativo mejore día a día, para que así este pueda lograr sabiduría en la práctica.

\section{CONCLUSIONES.}

La mediación es una ciencia que requiere de desarrollo de principios tanto morales, como éticos, y aquellos profesionales que la practican son de facto, movidos por estos principios éticos, técnicos y científicos, promueven que la práctica del mediador está en constante crecimiento.

Debido a estos grandes aportes que se desarrollan día a día en los mecanismos alternativos para la solución de controversias, es importante destacar que estos cambios en el uso de virtudes cotidianas también influyen las nuevas formas de convivencia, estilos de vida.

El mediador no es ajeno a los diversos valores y normas contemporáneas, que son propias de la época, aunque puede parecer que las normatividades y leyes son flexibles, en lo que respecta a la práctica del mediador no es más que un reflejo por el contexto que se vive y no fruto de una moral permanente.

Existe, por un lado, la percepción común de ciertos profesionales en mediación y personas en general, que consideran que la mediación se fundamenta en virtudes atemporales, con elevados propósitos morales, y que aquellos que la ejercen tienen como compromiso desinteresado contribuir a ayudar a las personas a entenderse a ellas mismas y así lograr una mejor convivencia con sus cercanos. 
Es por tal motivo, que la práctica del mediador se vuelve factor clave para analizar y conocer profundamente, ya que lo que ella implica no solo son conocimientos teóricos y científicos, no basta con saber actuar en situaciones con normas objetivas o aspectos técnicos, se requiere actuar con un profundo conocimiento interno para poder actuar de la mejor manera cuando algo no está previsto o se sale de contexto, y dada la naturaleza de la misma profesión se presenta constantemente, es por esto, que el mediador debe de seguir generando conocimiento no solo técnico, se precisa profundizar en lo que respecta al conocimiento del propio ser humano, se requiere sabiduría en la práctica, pero para que ésta sabiduría se pueda llevar acabo de la mejor manera, se requiere la apertura a nuevas formas, en las cuales el profesional pueda seguir creciendo, como lo son las virtudes. Estas no vienen a ser una imposición, son el puente que ayudan a cumplir el fin, abriendo el panorama para desarrollar nuevas habilidades, y seguir fomentando la parte humana a la par de la profesional, que les darán herramientas adicionales para que ayuden a las partes a solucionar sus controversias, entendiendo así que si el propósito del mediador transformativo, no solo se centra en la solución de las controversias. Al desarrollar virtudes, el mediador ayuda a las partes a ser mejores seres humanos.

\section{BIBLIOGRAFÍA}

Antonelli, M. (2013). Vitalismo y de subjetivación. La ética de la prudencia en Gilles Deleuze. Signos Filosóficos, vol. $\mathrm{XV}$, 89-117.

Araiza, J. (2009). Die aristotelischen Ethica Megala: Eine philosophische Interpretation. Münster: Lit Verlag.

Araiza, J. (2014). La prudencia en Aristóteles: una héxis praktikè*. Tópicos, Revista de Filosofía, 151-174.

Arboleda López, A. (2014). La conciliación. una mirada desde la bioética y la virtud de la prudencia. Revista lasallista de investigación, 192-202.

Aristóteles (1954). La política. Barcelona: Editorial Iberia.

Aristóteles (2011). La poética. Madrid: Gredos.

Aristóteles. (2000). Retórica. Madrid: Alianza.

Aubenque, P. (1963). La prudence chez Aristote. París: Presses Universitaires de France.

Birle, P. (2016). Pensar América Latina. Enfoques teóricos y espacios de reflexión. Introducción. IBEROAMERICANA. América Latina - España - Portugal, 16, 8-12. doi:10.18441/ibam.16.2016.63.7-13

Caponnetto, A. (2000). Retórica, Historia y Poesía en el pensamiento de Aristóteles. Buenos Aires: Gladius.
Chillón, J. M. (2019). Heidegger y la prudencia aristotélica como protofenomenología. Ideas y Valores, no. 68, 133-152. doi:http://dx.doi.org/10.15446/ideasyvalores. v68n169.63566

de la Oliva Santos, A. (2012). Prudencia versus Ideología: “De nuevo sobre el papel del juez en el proceso civil". Revista lus et Praxis, No 2, 243-294.

Deleuze, G. (2005). Pourparlers. París: Minuit.

González, D. (2009). Emociones responsabilidad y derecho. Madrid: Marcial Pons. Filosofía y Derecho.

Heidegger, M. (2002). Interpretaciones fenomenológicas sobre Aristóteles. Trad. Jesús Adrián Escudero. Madrid: Trotta.

Hoyos, C. (2005). La conciliación un modelo bioético hermenéutico. Bogotá: Señal.

Jajamovich, G. (2020). La circulación de conocimientos, saberes y políticas urbanas en América Latina. Introducción. CONICET-Instituto de Estudios de América Latina y el Caribe-Universidad de Buenos, 74, 8-11. doi:10.18441/ ibam.20.2020.74.7-11

Kurz, A. (2020). Pensamiento religioso, retórica y republicanismo en las Memorias de fray Servando Teresa de Mier. IBEROAMERICANA. América Latina - España - Portugal, 74, 172-182. doi:10.18441/ ibam.20.2020.74.171-183

Lorenzo Izquierdo, D. (2019). La virtud de la prudencia en el pensamiento de Alasdair Macintyre. Revista de Filosofía, vol. 76, 75-91.

Maclntyre, A. (1984). After Virtue: A Study in Moral Theory. Indiana: Press.

Maclntyre, A. (1988). Whose Justice? Which Rationality? Indiana: University of Notre Dame Press.

MacIntyre, A. (1990). Three Rival Versions of Moral Enquiry: Encyclopaedia, Genealogy, and Tradition. London: Duckwort.

Maclntyre, A. (1999). Dependent Rational Animals: Why Human Beings Need the Virtues. Chicago: Open court.

Maclntyre, A. (1999). Social Structures and their Threats. Royal Institute of Philosophy, vol. 74, 311-329

Malaver, R. (2012). Argumentación para la educación. Bogotá: Universidad Distrital Francisco José de Caldas.

Malaver, R., \& Moreno, J. (2019). El discurso de la prudencia para una buena argumentación. Folios, 83-94. doi:10.17227, № 49, 83-94

Marafioti, R. (2003). Los patrones de la argumentación. Buenos Aires: Biblios

Moreno Villares, J. (2014). Prudencia, virtud indispensable. Cuadernos de Bioética, vol. XXV, 105-110. 
Muñoz, Á. (2006). Del sentimiento de la prudencia o la mano invisible de la moral. Lecturas de Economía, No. 65, 223-240.

Pastor, M. (2020). La retórica panegírica en los primeros relatos de la conquista de México*. IBEROAMERICANA. América Latina - España - Portugal, 74, 152-168. doi:10.18441/ibam.20.2020.74.151-169

Pastor Seller, E. (2014). La mediación como servicio público de la administración local en las sociedades relacionales contemporáneas. Revista Brasileira de Gestäo e Desenvolviento Regional, 10 (1), 3-27 https://www.rbgdr.net/ revista/index.php/rbgdr/article/view/1208

Plantin, C. (2015). La argumentación. Barcelona: Planeta.

Perelman, C. y Tyteca, L.O. (1989). Tratado de la argumentación. Nueva retórica. Madrid: Gredos.

Platón (2003). Diálogos. Volumen II: Gorgias. Madrid: Editorial Gredos

Racionero, Q. (1999). Retórica de Aristóteles. Madrid: Gredos S.A.
Román, C. (2018). Figuraciones verbales y visuales de as lectoras de prensa. IBEROAMERICANA. América Latina - España - Portugal, 67, 102-126. doi:10.18441/ ibam.18.2018.67.101-126

Sáenz, K; Pastor Seller, E; Tamez, G. (2016). Human Development in fragmented societies. Pamplona: Aranzadi Thompson Reuters.

Sánchez, S. (2018). Cuando aparecen los otros. Modos de narrar las transformaciones del neoliberalismo en Los acuáticos de Marcelo Cohen. IBEROAMERICANA. América Latina - España - Portugal, 67, 144-160. doi:10.18441/ ibam.18.2018.67.143-160

Suñol, G. C. (2007). La Retórica y la Poética de Aristóteles: sus puntos de confluencia. La Plata: Departamento de Filosofía Universidad Nacional de La Plata, vol. 60, pp.79-111.

Weston, A. (1994). Las claves de la argumentación. Barcelona: Ariel S.A 